\title{
O uso de plantas da Amazônia na produção de bioprodutos para tratamentos de pele
}

\author{
The use of amazon plants in the production of bioproducts for skin treatments \\ Layna Kaanda Souza Pires ${ }^{1}$, Marcos Grigolin Grisotto ${ }^{2,3}$, Rosely Fontes Grisotto ${ }^{1}$
}

\begin{abstract}
Resumo: O mercado dos produtos cosméticos vem crescendo a uma taxa anual de cerca de 10\%, e com a crescente tendência de preservação ambiental, as indústrias de cosméticos tem voltado suas pesquisas para obtenção de bioprodutos derivados de plantas da região amazônica para o desenvolvimento de novos produtos naturais para mercado da beleza. No curso das mudanças globais, do "desenvolvimento sustentável" e da valorização dos recursos naturais, os setores industriais tem procurado reduzir os impactos ambientais e o uso de recursos não renováveis, como também, internalizar processos produtivos mais adequados neste concorrido setor industrial. Esta revisão tem como objetivo avaliar as informações a respeito de sete espécies vegetais da região amazônica atualmente utilizadas para formulações de produções de bioprodutos na área de estética. As espécies revisadas através de dados de meta-análise foram: açaí (Euterpe oleracea), andiroba ( Carapa guianensis), bacuri ( Platonia insignis ), castanha-doPará ( Bertholletia excelsa ), buriti ( Mauritia vinifera ou M. flexuosa), cupuaçu ( Theobroma grandiflorum ) e murumuru ( Astrocaryum murumuru ). Com base nos artigos analisados, estão descritas as principais características físico-químicas e compostos que podem possuir atividades relacionadas seus efeitos benéficos.
\end{abstract}

Palavras-chave: : Amazônia; bioprodutos; biodiversidade.

\begin{abstract}
The cosmetics market has been growing at an annual rate of around $10 \%$, and with the growing trend of environmental preservation concept, the cosmetics industry has turned its research to obtain bioproducts derived from plants from the Amazon region for the development of new products to the beauty market. In the course of global change, "sustainable development" and the appreciation of natural resources, industrial sectors have sought to reduce environmental impacts and the use of non-renewable resources, as well as to internalize more adequate production processes in this highly competitive industrial sector. This review aims to evaluate the information about seven plant species of the Amazon region currently used for formulations of bioproducts in the area of aesthetics. The species reviewed through meta-analysis data were açaí (Euterpe oleracea), andiroba (Carapa guianensis), bacuri (Platonia insignis), Brazil nut (Bertholletia excelsa), buriti (Mauritia vinifera or M. flexuosa), cupuaçu (Theobroma grandiflorum) and murumuru (Astrocaryum murumuru). Based on the articles meta-analyzis, the main physico-chemical characteristics and compounds that may have activities related to their beneficial effects are described.
\end{abstract}

Key Words: Amazônia; bioproducts; biodiversity.

1 - Enfermeira e Bacharel em Estética e Cosmetologia - UNICEUMA. E-mail: laynakaanda@hotmail.com

2 - Docente do Mestrado em Biologia Parasitária - UNICEUMA

3 - Docente - Instituto Florence

Rev. Investig. Bioméd. São Luís, 9:78-88, 2017 
Introdução

A biodiversidade da flora brasileira representa uma grande vantagem para produção de cosméticos para tratamentos de pele. Isso se deve a grande diversidade de matéria-prima, já que o país possui uma das maiores reservas de recursos naturais, diversos biomas e a mais rica biodiversidade tropical do mundo. Estima-se que o Brasil concentre boa parte do total mundial de espécies inventariadas, sendo que as plantas e os microrganismos existentes no território brasileiro, em especial na região Amazônica, se destacam dentre toda essa megabiodiversidade ${ }^{1}$.

A Amazônia é a maior reserva de biodiversidade do planeta, sua área equivale a $5 \%$ da superfície da Terra. Essa biodiversidade está avaliada em US\$ 2 trilhões, quantidade que pode parecer relativamente modesta para uma área que compreende grande parte das reservas genéticas do planeta ${ }^{2}$.

A utilização de plantas como medicamentos pela humanidade é tão antiga quanto à história do próprio homem. O processo de evolução da "arte de curar" se deu de forma empírica em processos de descobertas por tentativas com erros e acertos ${ }^{3}$. O avanço científico fez com que ressurgisse o interesse por pesquisas na utilização de plantas medicinais para terapêutica medicinal, visto ser um tratamento simples e de baixo custo, sendo que muitas plantas têm demonstrado propriedades nutritivas, remineralizantes, condicionadoras, hidratantes, anti-inflamatória, antiacne, repelente natural, pós-solares, cuidados capilares, etc ${ }^{4}$.

Seguindo a tendência dos produtos "naturais", "orgânicos", "verdes" ou "bio", os mercados consumidores apresentam atualmente crescente sofisticação e novas exigências quanto ao desempenho dos produtos naturais que incorporam a biodiversidade vegetal frente aos produtos convencionais do setor em geral. Essa tendência tem sido observada em várias partes do mundo, inclusive, nos países da União Europeia, Estados Unidos e Japão, que possuem mercados mais consolidados e cada vez mais adeptos dessas campanhas. Estudos do segmento apontam que o mercado internacional de produtos naturais para cuidado pessoal segue em crescimento médio anual avaliado entre $8 \%$ e $25 \%$ enquanto que mercados de produtos sintéticos apresentam evolução inferior, variando entre $3 \%$ e $10 \% \%^{5}$. A fitocosmética é o segmento da ciência cosmetológica que se dedica ao estudo e à aplicação dos conhecimentos da ação dos princípios ativos extraídos das espécies do reino vegetal, em proveito da higiene, da estética, da correção e da manutenção de um estado normal (eudérmico) e sadio da pele e cabelo ${ }^{6}$. Neste sentido, a biodisponibilidade de matérias-primas, principalmente as nativas, promove o desenvolvimento de novos bioprodutos, especialmente nos setores de cosméticos. Nos últimos anos, houve um grande aumento do uso de plantas originárias da região amazônica pelas indústrias de cosméticos no Brasil e mundialmente, devido à grande demanda do mercado mundial de $\operatorname{cosméticos}^{7,4}$. Para que um produto natural venha a se tornar um cosmético é necessário a realização de procedimentos de certificação pelos quais se verificam 0 processo de extração e produção de um produto, seguindo as normas às quais está subordinado. No caso dos orgânicos, é o instrumento que garante que os produtos orgânicos portadores do selo/ rótulo/ certificados foram produzidos de acordo com as normas de suas práticas ${ }^{8}$.

Este trabalho tem por objetivo revisar as informações sobre as propriedades das matérias-primas que são utilizadas na fabricação de bioprodutos cosméticos derivados plantas da região amazônica. Dentre as espécies vegetais que podem ser 
utilizadas e que atualmente estão sendo pesquisadas e trabalhadas para produção cosméticos naturais destacamse: Açaí, Andiroba, Buriti, Castanha-doPará, Copaíba, Cupuaçu e Murumuru. As propriedades destas espécies vegetais serão descritas nesta revisão.

\section{Coleta de Dados}

Esta revisão foi feita através de meta-análise de artigos publicados em revistas reconhecidas nacional e internacionalmente. Os principais foram: Inflamm Res., Acta Cir Bras., ConScientiae Saúde, International Journal of Nutrology, Journal of Ethnopharmacol, entre outras. Os trabalhos incluídos nesta revisão foram publicados no período entre 1984 e 2014. A identidade de cada planta foi verificada e baseada na descrição presente nos trabalhos utilizados para a pesquisa. Foram selecionadas 7 (sete) plantas para o estudo: Açaí, Andiroba, Buriti, Castanha-do-Pará, Copaíba, Cupuaçu e Murumuru.

\section{Fitocosmética}

No âmbito das múltiplas disciplinas que constituem a cosmética moderna, a fitocosmética é uma das que, atualmente, ocupam lugar de destaque graças ao aprofundamento científico e tecnológico que veio a resgatar a credibilidade e a seriedade, frequentemente arranhadas, na utilização de produtos de origem vegetal ${ }^{9}$. A escolha das plantas e seus derivados são preferencialmente classificados de acordo com seus efeitos farmacológicos para a produção dos fitocosméticos, e de acordo $\mathrm{com}^{9}$, distinguem-se em: adstringentes, tônicos, emolientes, umectantes, antissépticos, hipertêmicos, tintoriais, anti-inflamatórios, estimulantes, dentre outros. Pesquisadores definem diferentes categorias de cosméticos: natural, orgânico e feito com matéria-prima orgânica.
Cosmético natural: [...] o produto tem que ter ao menos um ingrediente "derivado de" uma substância natural, extraído diretamente de uma planta, porém não é produzido por síntese. Entretanto, não há definição legal do teor mínimo de ingrediente derivado de produto natural para se caracterizar 0 cosmético como natural ${ }^{8}$.

Cosmético orgânico: [...] a formulação do mesmo contiver pelo menos $95 \%$ de matérias-primas certificadas orgânicas, descontando-se a água e 0 sal. Os $5 \%$ restantes da formulação podem ser compostos por matérias-primas naturais, provenientes de agricultura ou extrativismo não certificadas ou permitidas para formulações. Cosmético feito como matéria prima orgânica: [...] no mínimo $70 \%$ e no máximo $95 \%$ dos componentes da formulação, descontando-se água e sal, forem certificados orgânicos. O restante da formulação pode ser composto por água, matérias-primas naturais, provenientes de agricultura ou extrativismo não certificados ou permitidos para formulações orgânicas ${ }^{10}$.

\section{Plantas da região amazônica utilizadas em cosméticos para tratamentos de pele}

\section{AÇAí (Euterpe oleracea Mart.)}

O açaí (Euterpe oleracea Mart.) é um fruto típico e popular da região amazônica, que nos últimos anos ganhou importância devido aos benefícios à saúde, associados a sua composição fitoquímica e a capacidade antioxidante. O Brasil é o principal produtor, consumidor e exportador do açaí. Esse fruto é comercializado e consumido pela população local nas regiões produtoras do Pará, Maranhão, Amapá, Acre e Rondônia ${ }^{11,12}$

Os antioxidantes apresentam propriedades antiflogísticas e reduzem a 
lesão tecidual $^{13,14}$. No açaí, além da ação dos antioxidantes, a composição lipídica do açaí pode estar envolvida na redução do processo inflamatório e da nocicepção (percepção de dor) $^{15}$. O envelhecimento está relacionado a várias causas. Uma dessas razões se baseia nos efeitos dos danos oxidativos às macromoléculas, que progressivamente se acumulam nas células, com o aumento da idade ${ }^{16,17}$. Estudos realizados demonstraram que a superexpressão do superóxido desmutase 1 (SOD1) pode aumentar a longevidade, enquanto mutações do SOD1 reduziram a longevidade em Drosophila melanogaster ${ }^{18-21}$. SOD1 é a maior enzima citosólica capaz de remover amplamente radicais superóxido reativos e tóxicos que são gerados em processos metabólicos na célula ${ }^{22}$. O consumo de açaí prolonga o efeito da SOD $^{18}$.

A grande concentração de polifenólicos da polpa tem alta capacidade de eliminação dos radicais superóxido e peroxil $^{18}$, propondo que 0 açaí tem propriedades de antienvelhecimento que possam ser utilizados na fabricação de bioprodutos.

\section{ANDIROBA (Carapa guianensis Aublet.)}

A andiroba (Carapa guianensis Aublet.), pertence à família botânica Meliaceae 23. A Carapa guianensis é árvore amplamente conhecida e utilizada como planta medicinal na região da Mata Amazônica. No Brasil, ela é conhecida popularmente como andiroba, carapa e carapinha $^{23}$. Comunidades tradicionais da Amazônia utilizam sabão de óleo de semente de Carapa guianensis para o tratamento de doenças de pele, artrite, reumatismo, infecções, feridas, contusões e como repelente de insetos ${ }^{24}$. Diversos estudos apontaram atividade anti-inflamatória, analgésica e antialérgica desse óleo ${ }^{25,26}$.

Em análise realizada por Castro $^{27}$, a maior porcentagem de ácido graxo na Andiroba é de ácido oléico com $52 \%$. 0 ácido oléico é um ácido graxo essencial (ômega 9), o qual participa do nosso metabolismo, desempenhando um papel fundamental na síntese dos hormônios. É muito utilizado como aditivo em base de sabões e sabonetes, para dar lubrificidade e emoliência. Também é muito encontrado em cremes e emulsões cosméticas pelas suas propriedades emolientes e para recompor a oleosidade em peles ressecadas e com problemas de escamação. São utilizados também na produção de bronzeadores, produtos solares e pós-solares devido a sua capacidade de proteção e regeneração da pele de danos e queimaduras causados pelos raios solares ${ }^{28}$.

O conhecimento das propriedades físico-químicas, como o índice de acidez e principalmente a distribuição graxa do óleo de andiroba é muito importante para o direcionamento na aplicação do mesmo em bioprodutos. O teor e a composição dos insaponificáveis presentes no óleo podem servir como marcadores químicos e atestar o grau de pureza dos óleos de andiroba comercializados. Além disso, podem principalmente viabilizar a sua aplicação na indústria farmacêutica e/ou cosmética, possibilitando a comprovação de benefícios ${ }^{27}$.

\section{BURITI (Mauritia flexuosa L.)}

A palmeira buriti (Mauritia flexuosa L.) foi muito importante para as tribos indígenas da América do Sul, considerada o sustento desses povos, que dela obtinha madeira, palha, óleo e fibras. Os frutos do buriti foram e ainda são de fundamental importância na dieta dessas populações, devido, principalmente à grande quantidade de vitamina contida em sua polpa ${ }^{28}$.

O fruto possui diversas finalidades, sendo utilizado desde a polpa até as sementes. O óleo do buriti atua como potencializador da proteção solar e como fonte de carotenóides (previne doenças cardiovasculares), pró-vitamina A e vitamina $\mathrm{E}$ (tocoferóis), antioxidantes naturais em produtos cosméticos, 
capilares e farmacêuticos. Além de ser uma grande fonte de ferro, cálcio, óleo e de fibras, considerado assim, um alimento funcional ${ }^{28,29}$.

$\mathrm{Na}$ composição química do buriti (Mauritia flexuosa L.), são encontrados ácidos graxos oleicos, palmíticos, ácido ascórbico e os carotenóides ${ }^{30}$. O interesse por suas utilidades medicinais gera uma especial atenção das comunidades tradicionais ${ }^{31}$. 0 óleo de buriti tem a função de lubrificar e regenerar a barreira hidrolipídica da pele frequentemente submetida a lesões ${ }^{32}$. Também quando usado em produtos pós-sol, o óleo de buriti evita danos provocados por radiação UV, justamente por apresentar propriedades fotoprotetoras ${ }^{33}$.

\section{CASTANHA-DO-PARÁ excelsa)}

De acordo com o IBGE $(2006)^{34}$, a castanha também é outro produto regional de grande destaque no mercado de cosméticos, porém, diferente de outras matérias-primas que são cultivadas, as sementes são coletas em florestas localizadas principalmente em sub-regiões do Acre, Amazonas e Pará, que concentram juntos mais de $80 \%$ da produção. Seu padrão de produção está basicamente circunscrito às reservas extrativistas ou áreas de coleta em núcleos isolados e normalmente integradas às unidades de beneficiamento de diversos produtores cooperados e extrativistas da região, sobretudo no estado do Acre ${ }^{35,36}$. Seus constituintes químicos são: ácido alfalinoléico, ácido linoleico, ácido oleico, ácido palmítico, ácido esteárico, antimônio, cálcio, cério, césio, escândio, esteróis, európio, éter estearina, excelsina, ferro, fósforo, iodo, itérbio, lantânio, lutécio, oleina, proteínas, samário, selênio, tântalo, tugnésio e vitamina $\mathrm{B}^{37}$. Possui propriedade umectante, formador de filme que impede a perda de água da pele. O óleo é rico em ácidos graxos insaturados, contém vitaminas $A, B, C$ e $E$, e minerais e oligoelementos. Originário do Brasil, da Região Amazônica, ocorre nos Estados do Acre, Amazonas, Pará Roraima e Rondônia. Usada em cosméticos como loções hidratantes, óleos de banho, sabonetes, etc. Nos cabelos, auxilia na restauração de cabelos danificados e desidratados. Na pele, pode ser usado como antioxidante no combate dos radicais livres para prevenir 0 envelhecimento cutâneo.

\section{COPAÍBA (Copaifera langsdorffii)}

As copaibeiras (Copaifera langsdorffii) são árvores comuns à América Latina e África Ocidental ${ }^{38}$, sendo encontradas, no Brasil, nas regiões Sudeste, Centro-Oeste e Amazônica.

Da árvore da copaíba é extraído um óleo-resina, de cor que varia de amarelo ouro a marrom ${ }^{39}$, dependendo da espécie. Esse óleo-resina tem sido utilizado desde a época da chegada dos portugueses ao Brasil na medicina tradicional popular e silvícola para diversas finalidades, e hoje se encontra como um dos mais importantes produtos naturais amazônicos comercializados, sendo também exportado para Estados Unidos, França, Alemanha e Inglaterra ${ }^{40}$.

O óleo-resina de copaíba é uma substância natural ${ }^{41}$ composta de uma parte sólida ${ }^{42}$, resinosa não volátil ${ }^{39}$ formada por ácidos diterpênicos ${ }^{41,42,40,43,44}$ responsáveis por 55 a $60 \%$ do óleo ${ }^{42}$ que, segundo FREIRE ${ }^{45}$, é utilizada como bálsamos, diluída na outra parte, um óleo essencial $^{39,41,42}$, composto de sesquiterpenos $^{42,45,40,43,44}$. Estes podem ser divididos em sesquiterpenos oxigenados (álcoois) e hidrocarbonetos sesquiterpênicos ${ }^{41}$ que possuem maior atividade antiinflamatória quando comparados aos outros dois grupos presentes ${ }^{47}$.

No ano de 1972, o FOOD AND DRUG ADMINISTRATION, órgão americano regulamentador de drogas, 
aprovou o óleo de copaíba, após ser submetido a testes de sensibilização e irritação, com o uso de 25 voluntários, obtendo-se resultado negativo para ambos $^{48}$.

As principais propriedades terapêuticas são: a atividade antiinflamatória 49,47,42,46,50,38,45,44,51,52.

O óleo de copaíba tem sido utilizado extensivamente, com diversas funções ${ }^{53}$. $\mathrm{Na}$ indústria de perfumes, 0 óleo essencial de copaíba é muito utilizado como um excelente fixador de odores, combinando perfeitamente suas notas frescas e acres com essências portadoras de notas florais ${ }^{48,41,51,44,54}$.

\section{CUPUAÇU (Theobroma grandiflorum)}

O cupuaçu (Theobroma grandiflorum Schum) é uma fruta típica da região Norte do Brasil, com grande potencial econômico.

Atualmente é a polpa que sustenta a produção, industrialização e comercialização desta fruta. A semente, um subproduto da industrialização da polpa, começa a despertar interesse como um produto de alto valor nutricional e com grande potencial de mercado para produtos industrializados ${ }^{55}$. Dentre os produtos fabricados com o cupuaçu, estão sendo fabricados os bioprodutos, com menos suprimentos artificiais.

Segundo Borges 56, o cupuaçu é rico em ácidos esteárico, oléico e araquídico. Possui um longo poder de duração em umectância. Auxilia na estabilidade de emulsões, toque agradável, maciez à pele, hidratação e reduz a perda trans-epidérmica de água. O óleo de cupuaçu apresenta alta concentração de ácidos graxos de cadeia longa, tais como oléico, araquidônico e berrênico, entre outros. Utilizado em cremes, loções, batons, óleos para banho, condicionadores e máscaras capilares, emulsões pós-barba, sticks, desodorantes cremosos e protetores solares.

MURUMURU (Astrocaryum murumuru)
A (Astrocaryum murumuru Mart.) está distribuída em todos os estados amazônicos, ao longo dos rios, nas áreas temporariamente inundadas e em formações florestais densas ou semiabertas. As comunidades amazônicas conhecem as propriedades fibrosas de suas folhas e estipe, seu palmito e óleo comestíveis $^{57,58}$. Apesar do seu potencial econômico, a espécie é pouco explorada comercialmente, provavelmente pela dificuldade em seu manuseio, visto que possui inúmeros espinhos. Atualmente existem no mercado produtos que utilizam como matéria-prima óleos extraídos de seus frutos, como por exemplo, o Cheysoap, um produto que reúne triglicerídeos saponificados de palmeiras do gênero Astrocaryum, utilizando-os como aditivos em formulações de sabonetes ${ }^{59}$.

Uma característica distintiva da palmeira, A. murumuru, são inúmeros espinhos mesmo sobre as sementes e flores. O óleo extraído da semente é branco e no estado sólido à temperatura ambiente $^{60}$. A manteiga de sementes pode ser adicionada aos produtos de cuidados da pele, shampoos e condicionadores devido o óleo possuir uma capacidade de retenção da água.

\section{Mercados para os cosméticos orgânicos e naturais}

Os cuidados com a aparência física representam diversas formas e tipos de comportamentos socioculturais e ao mesmo tempo revelam-se como importantes fios condutores de segmentos ligados direta ou indiretamente a essa indústria. Tais comportamentos estão sendo refletidos visivelmente no aumento do consumo de produtos cosméticos, sobretudo nas últimas décadas, desta forma têm influído claramente no crescimento da indústria de higiene pessoal, perfumaria e cosméticos, assim como nos serviços e setores transversais ${ }^{61}$.

Dados da ABIHPEC apontam para um crescimento médio anual de cerca de 
$10 \%$ da indústria brasileira de higiene pessoal, perfumaria e cosméticos, passando de um faturamento líquido de imposto sobre vendas, de $\mathrm{R} \$ 4,9$ bilhões em 1996 para $\mathrm{R} \$ 29,4$ bilhões em $2011^{62}$ (Figura 1).

Figura I - Evolução do Faturamento da Indústria de Higiene Pessoal, Perfumaria e Cosméticos no Brasil entre 1996 e 2011 (valores em bilhões de reais).

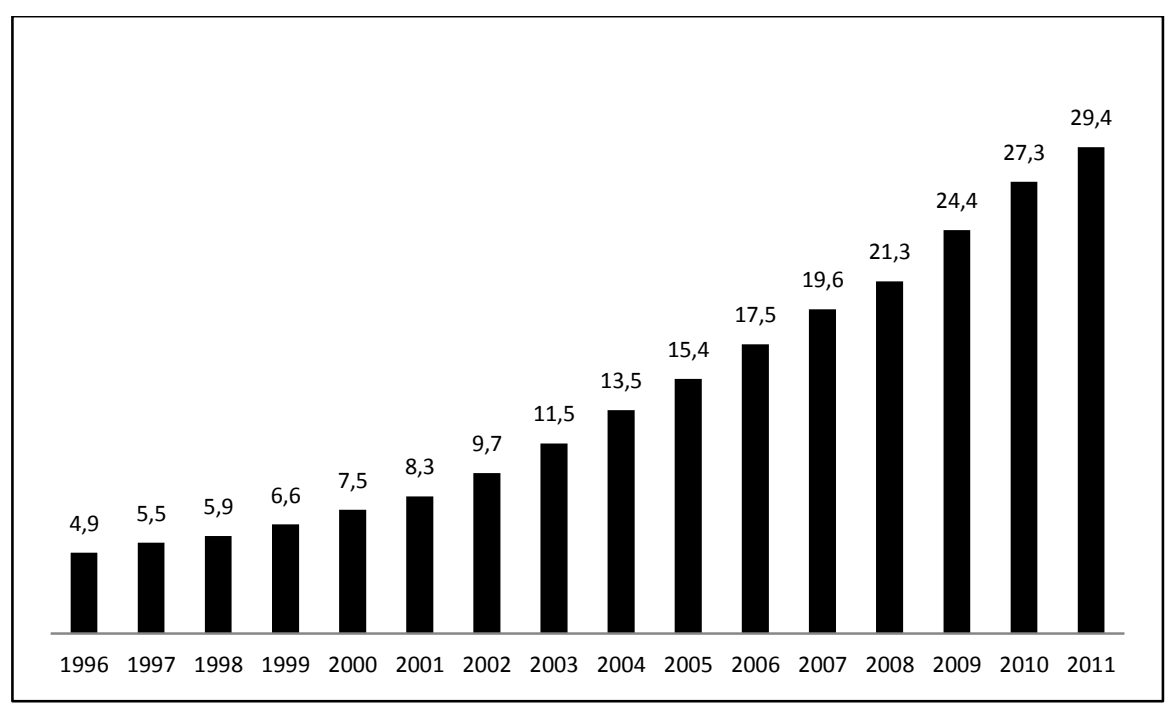

Fonte: ABIHPEC, 2012. (Produzido pela Autora)

No Brasil, os cosméticos, produtos de higiene e perfumes são definidos pela ANVISA (Agência Nacional de Vigilância Sanitária) como: "preparações constituídas por substâncias naturais ou sintéticas, de uso externo nas diversas partes do corpo humano, pele, sistema capilar, unhas, lábios, órgãos genitais externos, dentes e membranas mucosas da cavidade oral, com o objetivo exclusivo e principal de limpá-los, perfumá-los, alterar sua aparência e ou corrigir odores corporais e ou protegê-los ou mantê-los em bom estado"63 (ANVISA - RDC no 211/2005).

Conforme Miguel ${ }^{64}$, atualmente 0 acesso aos cosméticos tem sido cada vez mais amplo, podendo ser distribuídos por lojas especializadas, farmácias, drogarias, hipermercados, supermercados, websites das marcas ou revendedores da internet, "consultores" de venda direta, dentre outros.
Diversas opções de produtos para o rosto, os cabelos e o corpo são desenvolvidos para atender as demandas e expectativas dos consumidores, sendo elas pincipalmente ao longo das últimas décadas indicativas de uma preocupação com a juventude e os cuidados em relação ao corpo ${ }^{64}$.

Assim, comportamentos preventivos em relação à saúde do corpo se estendem em âmbito global, inspirando cuidados com o meio ambiente e o planeta como um todo", divulgando-se também nos meios de comunicação "o aumento dos problemas ambientais, dos desastres ecológicos, do surgimento de doenças e epidemias, como consequências naturais e das próprias atitudes humanas" ${ }^{\prime \prime 5}$.Os produtos formulados com ingredientes naturais têm incorporado diferentes valores e conceitos, atribuídos a uma sociedade que cada vez mais valoriza um estilo de vida saudável, a aparência, o bem-estar 
e que se preocupa com as questões ambientais. $^{65}$

\section{Considerações Finais}

Neste trabalho estão descritas diversas propriedades terapêuticas de produtos naturais presentes em plantas da região amazônica, indicando o grande potencial medicinal e econômico destas e outras espécies vegetais. As sete espécies vegetais abordadas nesta revisão representam uma pequena amostra do potencial da biodiversidade de plantas existentes na Amazônia, sendo que o Brasil encontra-se um uma posição estratégica em relação à extração e produção desses produtos naturais. Deve-se aproveitar essa grande evolução e crescimento do mercado nacional e mundial de cosméticos, visto o grande aumento do grau de preocupação que as pessoas têm demonstrado em relação à beleza, cuidados pessoais e higiene. Assim, a pesquisa e desenvolvimento de biocosméticos a partir de produtos naturais devem ser encaradas como estratégia para 0 desenvolvimento sustentável, podendo trazer benefícios á saúde, bem como promovendo o desenvolvimento regional e preservação da natureza. Este cenário é factível quando a extração é corretamente aprovada pela instituição responsável (IBAMA) através da liberação de licenças bem como fiscalização das as empresas responsáveis pela fabricação desses produtos.

\section{Referências}

1. Ministério do Meio Ambiente; Suframa. Superintendência da Zona Franca de Manaus; Sebrae. Serviço Brasileiro de Apoio às Micro e Pequenas Empresas. GTA. Grupo de Trabalho Amazônico. Produtos Potenciais da Amazônia. Relatório Técnico, Brasília: MMA, 1998. Disponível em: www.mma.gov.br. Acesso em novembro de 2016.

2. Bloise, M. I. Óleos vegetais e especialidades da floresta amazônica. Cosmetics \& Toiletries, v.15, n.05, p. 46-9,2003.

3. Mors, W.; Rizzini, C.T. Useful plants of Brazil. San Francisco: Holden-Day Inc., 1966. 45p.

4. Franquilino, E. Ativos Amazônicos. São Paulo: Cosmetics e Toiletries: 18-53, 2006, p. 19-47.

5. Euromonitor. Euromonitor Internacional: business inteligence, company profiles, strategic Market analysis. Disponível em: www.euromonitor.com Acesso em novembro de 2016.

6. Brito, ES.; Araújo, MC.P.; Alves, RE.; Carkeet, C.; Clevidence, BA.; Novotny, J A. Anthocyanins present in selected tropical fruits: acerola, jambolão, jussar and guajiru. Journal of Agricultural and Food Chemistry, v.55, p.9389-9394, 2007.

7. Baby, A.R. et al. Uso de extratos de plantas em cosméticos. São Paulo: Cosmetics \& toiletries 17(1): 78-82, 2005, p.78,80,81.

8. Neves, K. Cosméticos orgânicos e naturais: equilíbrio entre homem e meio ambiente. São Paulo: Cosmetics \& Toiletries 19 (4) 2833,2007, pág. 28, 29.

9. Labs, V.V.H. Fitocosmética. São Paulo: Cosmetics \& Toiletries 2: 9-14, 1990, pág 10.

\footnotetext{
10. Bispo, M. (2008) Cosméticos Verdadeiramente orgânicos. São Paulo: Cosmetics \& Toiletries 20:50-52.
} 
11. Menezes, SEM; Torres, AT; Srur, AUS. Valor nutricional da polpa de açaí (Euterpe oleracea Mart.) liofilizada. Acta Amazônica, v.38, n.2, p.311-316, 2008.

12. Homma, AEO; Frazão DAC. O despertar da floricultura amazônica. Floricultura em revista. Novembro, p.27-31, 2002.

13. Conner et al., 1996; Conner, EM.; Grisham, MB. Inflammation, free radicals and antioxidants. Nutrition, v. 12, p.274-277, 1996.

14. Cuzzocrea, S.; Riley, D. P.; Caputi, A. P.; Salveminl, D. Antioxidant therapy: a new pharmacological approach in chock, inflammation, and ischemia/reperfusion injury. Pharmacol Review, v.53, p.135-159, 2001.

15. Favacho, ASH.; Oliveira, BR.; Santos, KC.; Medeiros, BJL.; Souza, PJC.; Perazzo, FF.; Carvalho, JCT. Anti-inflammtory and antinociceptive activities of Euterpe oleracea oil. Brazilian Jornal of Pharmacognosy, v.21, n. 1, p. 105-114, 2011.

16. Del Pozo-Insfran, D.; Percival, S. S.; Talcott, S. T. Açaí (Euterpe oleracea Mart.) polyphenolics in their glycoside and aglycone forms induce apoptosis of HL-60 leukemia cells. J. Agric. Food Chem., v.54, p.1222-1229, 2006.

17. Pérez, V. I.; Bokov, A.; Van Remmen, H.; Mele, J.; RAN, Q.; Ikeno, Y.; RICHARDSON, A. Is the oxidative stress theory of aging dead? Biochim. Biophys. Acta, v.1790, n.10, p.10051014, 2009.

18. Sun, X.; Seeberger, J.; Alberico, T.; Wang, C.; Wheeler, C. T.; Schauss, A. G.; Zou, S. Açaí palm fruit (Euterpe oleracea Mart.) pulp improves survival of flies on a high fat diet. Exp. Gerontol., v.45, n.3, 243-251, 2010.

19. Philips, J. P.; Campbell, S. D.; Michaud, D.; Charbonneau, M.; Hilleker, A. J. Null mutation of copper/zinc superoxide dismutase in drosophila confers hypersensitivity to paraquat and reduced longevity. Proc. Natl. Acad. Sci. v.86, p.2761-2765, 1989.

20. Martin, I.; Jones, Ma.; Grotewiel, M. Manipulation of sod1 expression ubiquitously, but not in the nervous system or mescle, impacts age-related parameters in drosophila. FEBS Lett., v.584, p.2308-2314, 2009.

21. Landis, G. N.; Tower, J. Superoxide dismutase evaluation and life span regulation. Mech. Ageing Dev., v.126, p.365-379, 2005

22. Fridovich, I. Superoxide radical and superoxide dismutases. Annu. Rev. Biochem., v.64,p.97-112, 1995.
23. Boufleuer, N. T. Aspectos ecológicos da Andiroba (Carapa guianensis Aublet., Meliaceae), visando 0 seu manejo e conservação. 2004. 86f. Dissertação (Mestrado em Ecologia e Manejo dos Recursos Naturais) - Universidade Federal do Acre-Rio Branco, 2004. Disponível em: http://www.ufac.br/ensino/mestrado/mest_ecol ogia/ dissertacoes/NeuzaTeresinhaBoufleuer.pdf. Acesso em: nov/2016.

24. Hammer MLA, Johns EA. Tapping an Amazon plethora: four medicinal plants of Marajo island, Para (Brazil). J Ethnopharmacol. 1993; 40(1): 53-75.

25. Penido C, Costa Ka, Pennaforte RI, Costa MFS, Pereira JFG, Siani AC. Anti-allergic effects of natural tetranortriterpenoids isolated from Carapa guianensis Aublet on allergeninduced vascular permeability and hyperalgesia. Inflamm Res.2005;54 (7):295303.

26. Penido C, Conte FP, Chagas MSS, Rodrigues CAB, Pereira JFG, Henriques MGMO. Antiinflammatory effects of natural tetranortriterpenoids isolated from Carapa guianensis Aublet on zymosan-induced arthritis in mice. Inflamm Res. 2006; 55(11):457.

27. Castro, LH; Santos, OP; JR, MB. Extração e estudo de óleos essenciais da semente da Andiroba. XIV Encontro Latino Americano de Iniciação Científica e $X$ Encontro Latino Americano de Pós-Graduação- UNIVAP, 2011.

28. Silva, D. B.; Martins, R. C.; Agostini-Costa, T. S. Buriti. Série Frutas Nativas 2010.Edição Comemorativa dos 40 anos da SBF. Jaboticabal: Funep 2010. 52p; $21 \mathrm{~cm}$ (Série Frutas Nativas, 3)

29. Leal, A. F. Condições do extrativismo e aproveitamento das frutas nativas da microrregião de Teresina - Piauí. Mestrado em Desenvolvimento e Meio Ambiente. Universidade Federal do Piauí. 2005.

30. Ferreira EC, Malafaia O, Ribas-Filho JM, Heibel M, Baldez RN, de Vasconcelos PRL, Análise comparativa da cicatrização de pele como uso intraperitoneal de extrato aquoso de Orbignya phalerata (babaçu). Estudo comparativo em ratos. Acta Cir Bras. 2011;21:66-75.

31. Ferrão BH, De Oliveira HB, Molinari RF, Teixeira MB, Fontes GG, Amaro MOF,. Importância do conhecimento tradicional no uso de plantas medicinais em Buritis, MG, Brasil. Ciência e Natura, Santa Maria. 2014; 36 (Ed. Especial): 321-34. 
32. Zanatta, C.F. et al. Low cytotoxicity of creams and lotions formulated with buriti oil (Mauritia flexuosa) assessed by the neutral red release test. Food and Chemical Toxicology, v.46, p.2776-2781, 2008. Disponível em: <http:// w ww.sciencedirect.com/science / a r t i c I e / p i i / S0278691508002238>. Acesso em: nov/2016.

33. Zanatta, C.F. et al. Photoprotective potential of emulsions formulated with Buriti oil (Mauritia flexuosa) against UV irradiation on keratinocytes and fibroblasts cell lines. Food and Chemical Toxicology, v.48, p.70-75, 2010. Disponível em: <http://www.sciencedirect.com/science/article/ pii/ S0278691509004256>. Acesso em: Nov/2016.

34. IBGE. Instituto Brasileiro de Geografia e Estatística. Disponível em: www.ibge.org.br/. Acesso em dezembro/2016.

35. ADS. Agência de Desenvolvimento Sustentável do Amazonas (2011). Disponível em: www.ads.am.gov. Acesso em dezembro de 2016.

36. COOPERACRE. Cooperativa Central de Comercialização Extrativista do Acre (2012). Disponível em: www.cooperacre.com. Acesso em novembro de 2016.

37.PLANTAMED. Castanha-do-Pará. Acesso em 05/12/16:

http://www.plantamed.com.br/plantaservas/esp ecies/Bertholletia excelsa.htm.

38. Francisco, S.G. Uso do óleo de copaíba (Copaifera officinalis) em inflamação ginecológica. Femina, v.33, n.2, p.89-93, 2005.

39. Lloyd, J.U. Copaifera officinalis. Chicago: The Western Druggist, 1898. 13p.

40. Veiga Junior, V.F. et al. Plantas medicinais: cura segura? Química nova, v.28, n.3, p.51928, 2005.

41. Cascon, V.; Gilbert, B. Characterization of the chemical composition of oleoresins of Copaifera guianensis Desf., Copaifera duckei Dwyer and Copaifera multijuga Hayne. Phytochemistry, v.55, n.7, p.773-8, 2000.

42. Rigamonte Azevedo, O.C. et al. Copaíba: ecologia e produção de óleo-resina. Rio Branco: EMBRAPA, MAPA, 2004. 28p.

43. Oliveira, E.C.P. et al. Identificação da época de coleta do óleo-resina de copaíba (Copaifera spp.) no município de Moju-PA. Revista Brasileira de Plantas medicinais, v.8, n.3, p.1423, 2006.

44. Ramos, M.F.S. Desenvolvimento de microcápsulas contendo a fracão volátil de copaíba por spray-drying: estudo de estabilidade e avaliação farmacológica. 2006. 132p. Tese (Doutorado em Ciências Farmacêuticas), Universidade de São Paulo, Ribeirão Preto.

45. Freire, D.B. et al. Efeito dos óleos vegetais de andiroba (Carapa sp.) e copaíba (Copaifera sp.) sobre forídeos, pragas de colméias, (Díptera: Phoridae) na Amazônia central. Acta Amazônica, v.36, n.3, p.365-8, 2006.

46. Araújo Júnior, F.A. et al. Efeito do óleo de copaíba nas aminotransferases de ratos submetidos à isquemia e reperfusão hepática com e sem pré-condicionamento isquêmico. Acta Cirúrgica Brasileira, v.20, n.1, p.939,2005.

47. Maciel, M.A. et al. Plantas medicinais: a necessidade de estudos multidiciplinares. Quimica Nova, v.25, n.3, p.429-38, 2002.

48. Veiga Junior, V.F.; Pinto, A.C. O Gênero Copaifera L. Química nova, v.25, n.2, p.27386, 2002.

49. Vieira, L.S. Fitoterapia da Amazônia. 2.ed. São Paulo: Editora Agronômica Ceres, 1992. $347 p$

50. Brito, M.V.H. et al. Copaiba oil effect on urea and creatinine serum levels in rats submitted to kidney ischemia and reperfusion syndrome. Acta Cirúgica Brasileira, v.20, n.3, p.243-6, 2005.

51. Pacheco, T.A.R.C. et al. Antimicrobial activity of copaíba (Copaifera spp) balsams. Revista Brasileira de Plantas Medicinais, v.8, p.123-4, 2006.

52. Silva, F.H. et al. Estudo do óleo essencial e extrato hidrometanólico de Copaifera langsdorffii Desf (Caesalpinaceae) do cerrado e mata atlântica. In: REUNIÃO NACIONAL DA SOCIEDADE BRASILEIRA DE QUÍMICA, 29, 2006. Águas de Lindóia. Anais eletrônicos... São Paulo: Instituto de Química da USP, 2006. Disponível em <http://www.sbq.org.br/29ra>. Acesso em: 04/12/2016.

53. Pieri, F.A. Efeito (in vitro/ in vivo) do óleo de copaíba (Copaifera officinalis) sobre bactérias formadoras de placa dental em cães (Canis lupus Familiaris). 2007. 85p. Dissertação (Mestrado em Ciência Animal) Universidade José do Rosário Vellano, Alfenas.

54. Rigamonte Azevedo, O.C. et al. Potencial de produção de óleo-resina de copaíba (Copaifera sp.) de populações naturais do sudoeste da Amazônia. Revista Árvore, v.30, n.4, p.583-91, 2006. 
55. Carvalho, A.V.; Extration, concentration and functionary and physical-chemical characterization of proteins of cupuacu, 2004.

56. Borges, R.C.G.; Garvul, M. R.; Rosa, G. A. A. Produção de fitocosméticos e cultivo sustentável da biodiversidade no Brasil. Site: http://www.computacao.unitri.edu.br Acesso em: 02/12/2016.

57. Lorenzi, H.; Souza, H.M.; Medeiros-Costa, J.T.; Cerqueira, L.S.C.; Behr, N. 1996. Palmeiras no Brasil: exóticas e nativas. Nova Odessa: Plantarum. 303pp

58. Miranda, I.P.A.; Rabelo, A.; Bueno, C.R.; Barbosa, E.M.; RIBEIRO, M.N.S. 2001. Frutos de palmeiras da Amazônia. 1ed. Manaus: MCT INPA. p. 21-22.

59. Silva, C.R. 2003. Sabonetes biomiméticos com ativos da Amazônia. Cosmetics \& Toiletries, 5(15): 66-71.

60. Burlando, B. ; Verotta, L. Cornara, G. Bottinimassa, E. ; Princípios de ervas em cosméticos: Propriedades e mecanismos de ação. CRC Press, Taylor \& Francis Grupo: Boca Raton, 2010. Ação. CRC Press, Taylor \& Francis Grupo: Boca Raton, 2010.

61. Miguel, L.M. A biodiversidade na indústria de cosméticos: contexto internacional e mercado brasileiro. Programa de pós-graduação em Geografia Humana, USP, 2012.

62. ABIHPEC. Panorama do Setor: Higiene Pessoal, Perfumaria e Cosméticos. São Paulo: ABIHPEC, Relatórios (2008 a 2012).

63. ANVISA. Agência Nacional de Vigilância Sanitária. Disponível em: www.anvisa.gov.br/. Acesso em dezembro de 2016.

64. Miguel, L.M. A biodiversidade na indústria de cosméticos: contexto internacional e mercado brasileiro. Programa de pós-graduação em Geografia Humana, USP, 2012.
65. Rios, M. H. V. Anúncios de cosméticos antissinais: sinais de uma beleza jovem, saudável e atemporal. Dissertação (Mestrado em Comunicação Social) - Programa de PósGraduação em Comunicação Social, PUC, Belo Horizonte, 2010. 